\title{
Role of the ACE2-Ang-(1-7)-Mas axis in blood pressure regulation and its potential as an antihypertensive in functional foods (Review)
}

\author{
SHIQI LIN ${ }^{1,2}$, HUANGLEI PAN ${ }^{1}$, HONGLI WU ${ }^{1}$, DIFENG REN ${ }^{1}$ and JUN LU ${ }^{2}$ \\ ${ }^{1}$ Beijing Key Laboratory of Forest Food Process and Safety, Department of Food Science \\ and Engineering, College of Biological Sciences and Technology, Beijing Forestry University, \\ Beijing 100083; ${ }^{2}$ Beijing Engineering Research Center of Protein and Functional Peptides, \\ China National Research Institute of Food and Fermentation Industries, Beijing 100015, P.R. China
}

Received June 28, 2016; Accepted June 8, 2017

DOI: $10.3892 / \mathrm{mmr} .2017 .7168$

\begin{abstract}
The renin-angiotensin system (RAS) serves a critical role in blood pressure regulation and prevention of cardiovascular diseases. Efforts to develop functional foods that enhance the RAS have focused on inhibition of angiotensin-converting enzyme (ACE) activity in the ACE-angiotensin II (Ang II)-Ang II type 1 receptor axis. ACE2 and the Mas receptor are important components of this axis. ACE2 catalyzes Ang II into Ang-(1-7), which then binds to the G-protein-coupled receptor Mas. In addition, it induces nitric oxide release from endothelial cells and exerts antiproliferative, vasodilatory and antihypertensive effects. The present review examined recent
\end{abstract}

Correspondence to: Dr Difeng Ren, Beijing Key Laboratory of Forest Food Process and Safety, Department of Food Science and Engineering, College of Biological Sciences and Technology, Beijing Forestry University, 35 Tsinghua East Road, Haidian, Beijing 100083, P.R. China

E-mail: rendifeng@bjfu.edu.cn

Dr Jun Lu, Beijing Engineering Research Center of Protein and Functional Peptides, China National Research Institute of Food and Fermentation Industries, Building 6, Yard 24, Jiuxianqiao Middle Road, Chaoyang, Beijing 100015, P.R. China

E-mail: johnljsmith@163.com

Abbreviations: CVD, cardiovascular disease; RAS, reninangiotensin system; ACE, angiotensin-converting enzyme; ACE2, angiotensin-converting enzyme 2; Ang II, angiotensin II; Ang-(1-7), angiotensin-(1-7); $\mathrm{AT}_{1}$, angiotensin II type 1 receptor; $\mathrm{AT}_{2}$, angiotensin II type 2 receptor; $\mathrm{ACEi}$, angiotensin-converting enzyme inhibitors; ARB, angiotensin receptor blocker; NEP, neutral endopeptidase; SHR, spontaneously hypertensive rat; NO, nitric oxide; L-NAME, 1-nitro-arginine methyl ester; HP $\beta C D$, hydroxypropyl- $\beta$-cyclodextrin; XNT, xanthone

Key words: angiotensin-converting enzyme 2, angiotensin-(1-7), Mas receptor, renin-angiotensin system, antihypertensive effects, functional food findings regarding the physiological and biological roles of the ACE2-Ang-(1-7)-Mas axis in the cardiovascular system, discussed potential food-derived ACE2-activating agents, and highlighted initiatives, based on this axis, that aim to develop functional foods for the treatment of hypertension.

\section{Contents}

1. Introduction

2. ACE2-Ang-(1-7)-Mas axis and its biological characteristics

3. ACE2-Ang-(1-7)-Mas axis and regulation of blood pressure

4. Role of Ang-(1-7) in vasodilation and blood pressure regulation

5. Hypertensive activity and functional foods

6. Conclusions

\section{Introduction}

Cardiovascular disease (CVD) was responsible for $31 \%$ of all cases of mortality worldwide ( 17.5 million) in 2012 (1). Hypertension is a chronic symptom, which is strongly associated with CVD, and contributes to half of all cases of heart disease-associated mortality $(2,3)$. According to the World Health Organization, the total number of patients with hypertension will reach 1.56 billion in 2025 (4). As a major risk factor for CVD, hypertension may lead to stroke, coronary heart disease and peripheral artery disease, and the symptom severity intensifies with age $(5,6)$. Accordingly, $40 \%$ of adults worldwide $\geq 25$ years old have been diagnosed with hypertension, whereas CVD accounts for $\sim 80 \%$ of cases of mortality in low- and middle-income countries (7). Therefore, agents that regulate blood pressure and reduce hypertension are essential for controlling CVD $(2,3)$.

The pathogenesis of hypertension is incompletely understood. Hypertension is reportedly associated with numerous factors, including eating behavior, environmental parameters and familial inheritance $(8,9)$. In addition, it has been demonstrated that food peptides and their enzymatic hydrolysates 
exert an antihypertensive effect via numerous mechanisms, including angiotensin-converting enzyme (ACE) inhibition, renin and endothelin system suppression, supply of arginine for nitric oxide production, and inhibition of angiotensin receptors and calcium channels $(2,10,11)$.

The renin-angiotensin system (RAS) was discovered in 1898 (12), and serves various physiological and biological roles in blood pressure regulation, water-electrolyte metabolism, vascular tone, electrolyte balance, and heart and kidney signaling homeostasis by regulating the function of myocardial cells, fibroblasts and blood cells (13).

The ACE-angiotensin II (Ang II)-Ang II type 1 receptor $\left(\mathrm{AT}_{1}\right)$ axis concept is based on the function of several of the main components of the RAS (14). In systemic circulation, angiotensinogen forms a decapeptide, Ang I, by interacting with renin. Subsequently, ACE generates a physiologically active octapeptide, Ang II, by cleaving the C-terminal dipeptide His-Leu from Ang I (15). The physiological action of Ang II is mediated by $\mathrm{AT}_{1}$ and Ang II type 2 receptor $\left(\mathrm{AT}_{2}\right)$. $\mathrm{AT}_{1}$ is responsible for the majority of the physiological effects, such as regulating regional blood flow through binding of Ang II to $\mathrm{AT}_{1}$, leading to vasoconstriction and oxidative stress; accelerating thrombosis formation by stimulating adhesion molecules; and producing plasminogen activator inhibitor $(13,16,17)$. Conversely, $\mathrm{AT}_{2}$ in combination with Ang II lowers blood pressure and inhibits proliferation of malignant cells $(18,19)$. In addition, ACE induces vasoconstriction and blood pressure elevation by degrading bradykinin into inactivated fragments (20).

Treatment for hypertension tends to focus on the RAS, specifically ACE inhibitors (ACEi), Ang receptor blocker (ARB) and renin inhibitors (13). Food products, such as milk, fish, meat, egg, cereal, seeds, vegetables and fruits, exert antihypertensive effects via various mechanisms (21). Bioactive compounds, particularly food protein-derived peptides, contribute to regulation of blood pressure by interacting with the RAS and its associated pathways in the vascular system (2). Among these compounds, various food-derived ACE inhibitory peptides have been comprehensively studied (22). At present, there are two axes known to regulate the RAS: The classical ACE-Ang II-AT ${ }_{1}$ axis and the ACE2-Ang-(1-7)-Mas axis $(14,17)$. The ACE-Ang II-AT 1 axis may lead to CVD, including hypertension, stroke and coronary heart disease (19). Conversely, the ACE2-Ang-(1-7)-Mas axis serve a role in blood vessel protection, an effect reportedly mediated by hydrolysis of ACE2 $(19,20,23)$. ACE2 catalyzes degradation of Ang II into a heptapeptide, Ang-(1-7), which binds to the G-protein-coupled receptor Mas. Unlike Ang II, Ang-(1-7) reduces oxidative stress and protects the cardiovascular system (24). Therefore, the physiological balance between the ACE-Ang II-AT1 and ACE2-Ang-(1-7)-Mas axes is critical for the regulation of blood pressure and the prevention of CVD (25).

Knowledge of the ACE2-Ang-(1-7)-Mas axis has enabled development of functional foods that aim to prevent and/or regulate hypertension. ACE2, which is a major component of the ACE2-Ang-(1-7)-Mas axis, is a multifunctional enzyme that interacts with numerous biologically active substrates to exert its physiological effects; these substrates are considered activators of ACE2 and are abundant in natural food sources.
Compared with ACE, food protein-derived peptides that activate ACE2 have not yet been comprehensively studied. The present review discusses natural food substances that have the potential to activate ACE2, and highlights the biological characteristics, antihypertensive mechanisms and possible applications of the ACE2-Ang-(1-7)-Mas axis.

\section{ACE2-Ang-(1-7)-Mas axis and its biological characteristics}

Biological characteristics of ACE2. A comprehensive understanding of the biological characteristics of ACE2 is required for its therapeutic application. ACE2 is a human ACE-related carboxypeptidase that was discovered in 2000 by two research groups: By Tipnis et al (26) from a human lymphoma cDNA library and by Donoghue et al (27) from a human cardiac left ventricle cDNA library. The carboxypeptidase was named ACE homolog by Tipnis et al (26) and ACE2 by Donoghue et al (27); ACE2 was later adopted as the name. The ACE2 gene is localized to chromosome X (Xp22), contains 18 exons interspersed with 17 introns, and spans $\sim 40 \mathrm{~kb}$. The ACE2 gene product is a type I transmembrane glycoprotein of 805 amino acids. This glycoprotein includes a cytoplasmic end, a transmembrane domain and a conserved zinc metalloprotease consensus sequence. The predicted amino acid sequence of zinc metalloprotease exhibits significant homology with those of other members of the ACE family, with $42 \%$ similarity to human ACE $(15,28)$. The exons of the ACE2 gene have high sequence similarity to the first 17 exons of the ACE gene, suggesting a common ancestor gene (15).

Although the ACE and ACE2 genes have similar sequences, the physiological roles of their products vary. ACE increases blood pressure by hydrolyzing Ang I into Ang II, which binds to $\mathrm{AT}_{1}$ and $\mathrm{AT}_{2}$ receptors; however, $\mathrm{ACE} 2$ catalyzes the breakdown of Ang II to the counter-regulatory RAS peptides, Ang-(1-7) and Ang-(1-9) (29,30). This counter-regulatory effect occurs throughout the body: ACE2 has been observed in the plasma membrane of cells, in various organs and as a solute in plasma and urine $(29,30)$. ACE2 is known to have a regulatory function in the heart of ACE2 knockout mRen2 transgenic rats (31).

Ang I and Ang II are the primary substrates of ACE2 and necessary precursors of counter-regulatory RAS peptides: ACE2 catalyzes loss of one peptide from the C-terminal end of Ang I to generate Ang-(1-9), whereas a phenylalanine is lost from the C-terminal end of Ang II to form Ang-(1-7). The rate of catalysis of Ang II by ACE2 is 400-fold that of Ang I; therefore, the major role of ACE2 is to convert Ang II to Ang-(1-7) (32).

Synthesis and metabolism of Ang-(1-7). Other metabolites, such as Ang-(1-9), Ang-(1-7), Ang-(1-5), Ang-(2-8) and Ang-(3-8), exert regulatory activities similar to Ang I and Ang II. Research is at present focusing on Ang-(1-7), which is a heptapeptide consisting of aspartic acid, arginine, valine, tyrosine, isoleucine, histidine and proline $(10,33)$.

ACE2 provides an endogenous source of Ang-(1-7). Generation of Ang-(1-7) proceeds via at least three pathways (Fig. 1). Firstly, catalyzed by ACE2, prolyl endopeptidase or prolyl carboxypeptidase, the C-terminal residue of Ang II 


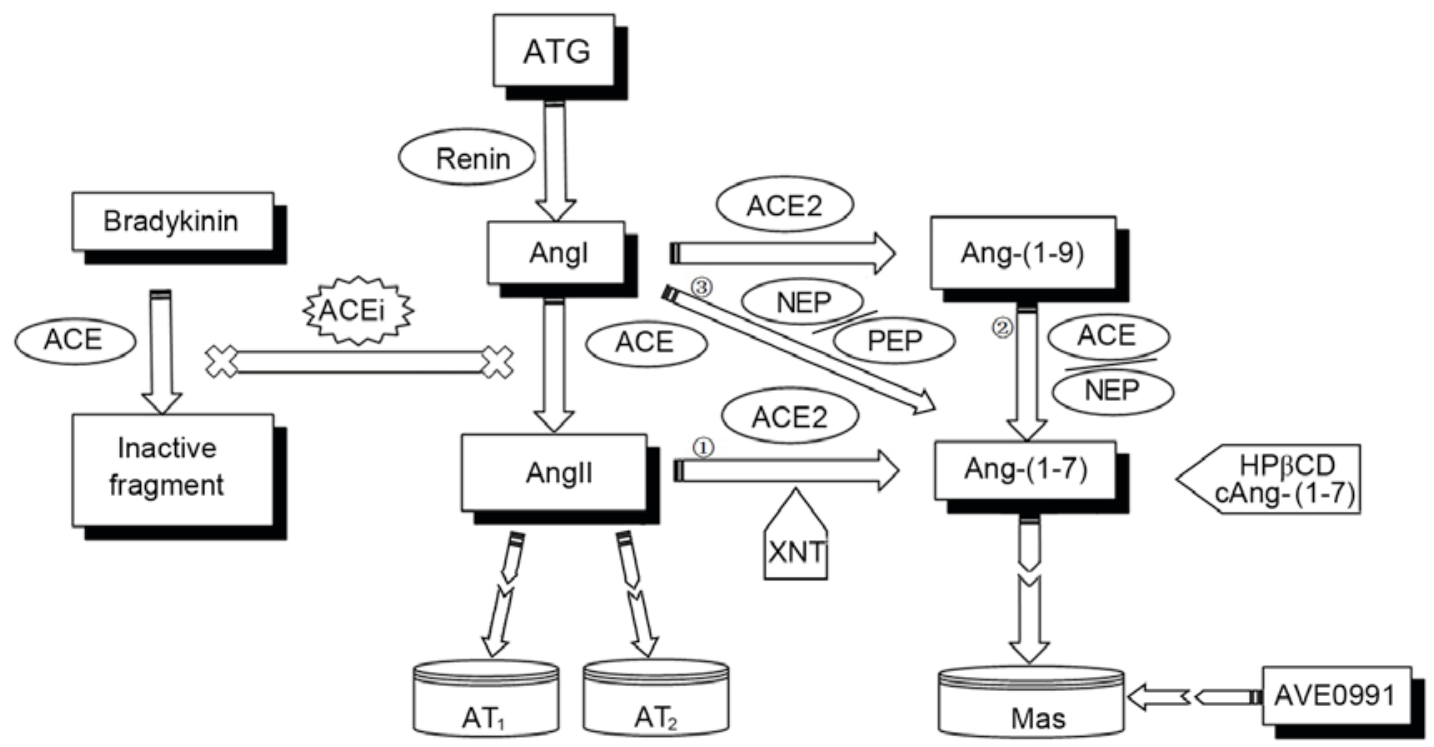

Figure 1. Renin-angiotensin system. ATG, angiotensinogen; Ang, angiotensin; ACE, Ang-converting enzyme; ACEi, ACE inhibitor; AT 1 , Ang II type 1 receptor; $\mathrm{AT}_{2}$, Ang II type 2 receptor; NEP, neutral endopeptidase; PEP, proline endopeptidase; XNT, xanthone; HP $\beta C D$, hydroxypropyl- $\beta$-cyclodextrin; cAng-(1-7), cyclic Ang-(1-7).

(Asp-Arg-Val-Tyr-Ile-His-Pro-Phe) is transformed into Ang-(1-7) (32,34). Secondly, cleavage of Ang I (Asp-Arg-ValTyr-Ile-His-Pro-Phe-His-Leu) by ACE2 generates the biologically inactive Ang-(1-9), and further cleavage of Ang-(1-9) by ACE or neutral endopeptidase (NEP) forms Ang-(1-7) (35). Thirdly, hydrolysis of the Pro-Phe bond of Ang I catalyzed by NEP or proline endopeptidase (PEP) results in production of Ang-(1-7). Since ACE2 has significantly greater catalytic activity with Ang II than Ang I, Ang-(1-7) is considered to be predominantly generated by the first synthesis pathway $(26,27,32)$. Hydrolysis of Ang I produces two peptides: Ang II and Ang-(1-7), which have mutually antagonistic physiological activities and are present in plasma at similar concentrations (36). Therefore, food-derived ACEi not only elevate the levels of Ang I by inducing Ang I formation through suppressing Ang II synthesis but also increase the plasma Ang-(1-7) level by reducing the rate of degradation of Ang-(1-7) to Ang-(1-5).

Ang-(1-7)-specific receptor and Mas receptor. In 1997, a high-affinity Ang-(1-7) receptor was detected in cultured bovine aortic endothelial cells by Tallant et al (37) using a radioimmunoassay. Subsequently, D-Ala7-Ang-(1-7) (A779) and D-Pro7-Ang-(1-7) were reported to exert specific antagonistic effects on Ang-(1-7) (38). In 2003, Santos et al (34) identified Mas as a functional receptor for Ang-(1-7). The Mas receptor is encoded by seven transmembrane G-protein-coupled receptors, and its endogenous conjugate. Fraga-Silva et al (39) initially reported a link between the Mas receptor and Ang-(1-7); expression of Ang-(1-7) was reduced in Mas receptor-deficient mice. In addition, concentration of the Mas receptor varied among rat cardiac cell types; the mRNA expression levels of the Mas receptor were low in cardiomyocytes, and high in coronary endothelial cells (39). Furthermore, high mRNA expression levels of the Mas receptor have been detected in coronary artery endothelial cells and smooth muscle cells (40). The Mas receptor is expressed in the human heart, thus suggesting an important role in cardiac function (41), and is also expressed in the brain, testis, kidney and blood vessels (42-44).

Following activation by Ang-(1-7), the Mas receptor induces vasodilation, and exerts antiproliferative, antifibrotic and antioxidative effects (42-44). Ferreira et al (45) suggested that Ang-(1-7) functions via Mas-mediated and non-Mas-mediated pathways. The predominant pathway involves Ang-(1-7) in Mas-mediated NO release, and this pathway can be partially suppressed by A-779 (46). Therefore, $\mathrm{G}$ protein-coupled receptor Mas appears to be a functional receptor of Ang-(1-7) (47).

\section{ACE2-Ang-(1-7)-Mas axis and regulation of blood pressure}

The role of ACE2 in blood pressure regulation. The biological characteristics of ACE2 are important for understanding the regulation of blood pressure. For example, ACE2 mRNA and protein levels are closely associated with blood pressure. Crackower et al (48) reported that ACE2 mRNA and protein levels were markedly reduced in strains of hypertensive rats, such as Sabra hypertensive rats, spontaneous hypertensive rats (SHRs) and spontaneously hypertensive stroke-prone rats. However, whether ACE2 contributes to reduced blood pressure, or reduced blood pressure suppresses ACE2 expression, is unclear.

The ACE2 gene is located on the $\mathrm{X}$ chromosome (Xp22) $(48,49)$, and is present in several hypertensive rat models (43), supporting a role for ACE2 in regulation of blood pressure. Crackower et al (48) reported significantly reduced myocardial contractility, and arterial and ventricular pressure, in ACE2-deficient C57BL/6 mice.

Knowledge of the physiological role of ACE2 in blood pressure regulation has facilitated the development of novel 
approaches for the prevention and treatment of hypertension, as well as novel antihypertensive functional foods. ACE2 exerts vasodilatory and cardioprotective effects, which not only affect resting blood pressure or cardiac contractility, but also significantly inhibit ventricular hypertrophy and renal fibrosis. ACE2 exerts dose-dependent effects in endogenous antihypertensive rats and SHRs. Therefore, ACE2 overexpression is typically used in investigations of hypertension regulation. Mercure et al (50) indicated that overexpression of Ang-(1-7) reduced Ang II-induced cardiac remodeling and relieved hypertension. Rentzsch et al (51) using an SHR model, demonstrated that overexpression of ACE2 in blood vessels reduced blood pressure and improved endothelial function. Overexpression of ACE2 may also protect the heart against myocardial remodeling after infarction in SHR models. Furthermore, ACE2 reduced hyperglycemia by preventing pancreatic RAS overactivation in high-fat diet-mediated type 2 diabetes (52). In the pancreas of mice administered ACE2, reduced Ang II levels and increased ACE2 activity were detected (52). However, it has been reported that arrhythmias may occur in mice with ACE2-overexpressing cardiac myocytes (53). This discrepancy is likely to be due to a difference in Ang-(1-7) concentrations, since Ang-(1-7) causes arrhythmia at higher concentrations but not at lower concentrations (54,55). Díez-Freire et al (56) reported that overexpression of ACE2 in SHRs using lentiviral vector; they concluded a protective effects on high blood pressure in lenti-ACE2-treated SHRs.

\section{Role of Ang-(1-7) in vasodilation and blood pressure regulation}

Ang-(1-7) exerts a vasodilatory effect on the arteries of pigs, dogs, cats and rats. This effect is associated with nitric oxide (NO), bradykinin, prostaglandin and endothelium-derived hyperpolarizing factor (46,57-60).

The vasodilatory effects of Ang-(1-7) are endothelium-dependent; it is absent when endothelial cells are removed or following application of 1-nitro-arginine methyl ester (L-NAME). Pinheiro et al (43) reported that short-term administration of Ang-(1-7) to C57BL/6 mice resulted in activation of the Mas receptor, which increased NO release and enhanced endothelial function. Conversely, Mas-knockout mice exhibited a greater release of reactive oxygen species and reduced release of NO. This imbalance between NO release and oxidative stress may result in endothelial dysfunction and hypertension in rats. Ang-(1-7) activates the Mas receptor in human vascular endothelial cells and causes vasodilation through renal hemodynamics by activating endothelial NO synthase (43).

Under normal physiological conditions, Ang-(1-7) in the plasma serves an important role in vasodilation and maintains a dynamic equilibrium with Ang II. This antagonistic effect of Ang-(1-7) with Ang II was reported by Roks et al (60) in the human thoracic artery, cardiac cells, vascular smooth muscle cells and fibroblasts.

Ang-(1-7) has a vital role in the central regulation of blood pressure. It increases baroreceptor sensitivity and regulates biological rhythms, such as blood pressure and heart rate. A previous study on SHRs and (mRen-2)27 hypertensive transgenic rats reported that cerebroventricular administration of an affinity-purified Ang-(1-7) antibody resulted in significant dose-related elevations in blood pressure, which were associated with tachycardia. Conversely, an anti-Ang II antibody induced a hemodynamic response that significantly decreased arterial pressure and heart rate (61).

Gironacci et al (62) proposed another mechanism underlying the effects of Ang-(1-7) using normotensive rats and SHRs. Administration of Ang-(1-7) significantly reduced the release of hypothalamic norepinephrine. This effect was reported to be blocked by NO synthase inhibitor, guanylate cyclase inhibitor, $\mathrm{AT}_{2}$ receptor antagonist, Ang-(1-7) receptor antagonist and bradykinin receptor antagonist, indicating that Ang-(1-7) suppresses norepinephrine release in the hypothalamus with the combined function of NO. This suggests the existence of a novel mechanism by which Ang-(1-7) regulates central blood pressure.

Ang-(1-7) also controls blood pressure by regulating electrolyte balance. Ang-(1-7) reportedly exerts diuretic and natriuretic effects, and regulates sodium and bicarbonate reabsorption in renal tubules (63). The effect was more marked in SHRs; i.e., Ang-(1-7) inhibited the release of antidiuretic hormone, which regulated aldosterone release and influenced reabsorption of tubular sodium and bicarbonate. However, this effect was relatively weak in normal rats. In cultured renal tubular epithelial cells, Ang-(1-7) increased the amount of arachidonic acid via the phospholipase A2 pathway, which inhibited intracellular and extracellular transport of sodium ions, and indirectly increased prostacyclin levels (64). Prostacyclin also facilitated the diuretic and natriuretic effects of Ang-(1-7) by dilating blood vessels and increasing membrane permeability (65).

Fontes et al (66) reported an indirect mechanism of Ang-(1-7)-Max axis regulation based on pulmonary endothelial cells; i.e., a reduction in cardiovascular risk by attenuation of emotional stress. Ang-(1-7) interacts with the Mas receptor in the basolateral amygdala, which attenuates anxiety in the brain and suppresses the cardiovascular response by regulating sympathetic outflow (67). Gironacci (68) provided evidence for this mechanism in the nucleus of the brain, baroreflex controlled heart rate and glucose metabolism in Sprague-Dawley rats, and blocked tachycardia and the pressor response in conscious male Wistar rats. These studies suggest novel mechanisms by which the ACE2-Ang-(1-7)-Mas axis regulates blood pressure; however, the site of action of Ang-(1-7) remains unclear $(66,67)$.

Role of the ACE2-Ang-(1-7)-Mas and ACE-Ang II-AT axes in blood pressure regulation. The kidneys of SHRs have decreased ACE2 mRNA and protein expression levels, and increased ACE mRNA and protein expression levels $(56,69,70)$. In addition, elevated concentrations of Ang II and Ang II-AT receptor have been observed in SHRs (71). This alteration is reflected by increased ACE-Ang II-AT 1 axis activity and decreased ACE2-Ang-(1-7)-Mas axis activity (13,14,20). Therefore, an imbalance between the ACE-Ang II-AT and ACE2-Ang-(1-7)-Mas axes is an important factor in hypertension.

The physiological balance between the two axes remains unclear. ACE2 functions as an endogenous enzyme that regulates RAS and the balance between the two axes (72). The 
latter depends predominantly on Ang-(1-7) and Ang II concentrations. Therefore, maintaining the balance between Ang II and Ang-(1-7) is important for regulating blood pressure (20). A slight imbalance of ACE2/Ang-(1-7) ratio can result in disease in the cardiovascular, kidney, lung and central nervous systems. However, the RAS system is not regulated by a single compound. Although Ang-(1-7) has an antagonistic effect on Ang II, increases in Ang-(1-7) levels do not necessarily lead to an antihypertensive effect. A high concentration of ACE2 and Ang-(1-7) may be harmful and result in fatal arrhythmias. Therefore, alteration of the concentration of any component of the angiotensin system could influence the expression of others. Ensuring the overall balance of the angiotensin system is considered the best solution for maintaining blood pressure homeostasis and normal physiological functions. In addition, the angiotensin system balance should be taken into consideration in the development of drugs and functional foods.

Targeting the ACE2-Ang-(1-7)-Mas axis. Antihypertensive drugs and functional foods typically target the ACE-Ang $\mathrm{II}_{-} \mathrm{AT}_{1}$ axis; e.g., ACEi, ARB and renin (Fig. 1). Although Ang-(1-7) has a marked effect on blood pressure, its use is subject to several limitations. For example, Ang-(1-7) has a short half-life (10-15 sec), and it is rapidly degraded by peptidases in the gastrointestinal tract (73). Therefore, it is necessary to develop a feasible method for increasing the stability of Ang-(1-7). Lula et al (74) prepared an Ang-(1-7) and hydroxypropyl- $\beta$-cyclodextrin (HP $\beta C D)$ inclusion complex, which increased the stability and absorption of Ang-(1-7). After oral administration, Ang-(1-7) was released and exerted an antihypertensive effect in the stomach and small intestine. A pharmacokinetic study also reported a long-term effect of orally administered HP $\beta C D /$ Ang-(1-7) in terms of an increased plasma Ang-(1-7) concentration, and enhanced myocardial remodeling and cardiac function (75).

Cyclization is another approach to preventing rapid degradation of Ang-(1-7) in the stomach and small intestine. A thioether-bridged analogue of Ang-(1-7), cyclic Ang-(1-7) [cAng-(1-7)], exhibited internal cyclization and increased biological stability (76). In the aorta of rats, the angiectatic effect of cAng-(1-7) was double that of Ang-(1-7). A study involving a rat model of myocardial infarction demonstrated that a subcutaneous injection of cAng-(1-7) suppressed left ventricular end-diastolic pressure and facilitated endothelial function (77). However, the infarct size was relatively small, and no evaluation of systolic function or cardiac fibrosis was performed. Further testing in numerous models is essential to enhance understanding of the beneficial effects of cAng-(1-7) (77).

Ang-(1-7) analogs also exert antihypertensive activity. The first Ang-(1-7) analog, AVE0991, was synthesized by Wiemer et al (78) in 2002. It is a non-peptide Mas receptor agonist that has the same active site as Ang-(1-7) and exerts similar effects in endothelial cells. Previous studies have demonstrated the antihypertensive effects of this agonist: i) AVE0991 stimulated the release of NO by bovine aortic endothelial cells, as well as in the blood vessels, kidneys and heart of mice (45,79-81); ii) AVE0991 exerted a vasodilatory effect on endothelial cells in the aortas of rats and mice; this effect was absent in Mas-knockout mice (79); iii) AVE0991 inhibited hypertension and organ damage of L-NAME in SHRs (82); iv) short-term administration of AVE0991 increased NO release and strengthened endothelial function (83); and v) AVE0991 exhibited a dose-dependent antihypertensive effect on deoxycorticosterone acetate-salt-induced hypertensive rats, which was amplified by aliskiren (84). Therefore, the combination of a renin inhibitor and Mas receptor agonist may be considered a potential treatment for hypertension.

ACE2 activators exert antihypertensive effects by increasing the expression of Ang-(1-7) and inhibiting extracellular regulated protein kinases (85). Therefore, ACE2 accelerators may be effective against hypertension. Prada et al (86) proposed the use of the ACE2 activator, xanthone (XNT), to activate the ACE2-Ang-(1-7)-Mas axis. Although the peptide sequence was not identified, XNT bound to an ACE2-specific pocket (86). Bolus injection of XNT to male Wistar-Kyoto rats and SHRs induced conformational changes in ACE2, which enhanced ACE2 activity and induced dose-dependent increases in bradykinin concentration $(86,87)$. In addition, XNT may reduce Ang II plasma concentrations and increase Ang-(1-7) concentration. The physiological functions of XNT include enhancing cardiac functionality and inhibiting renal fibrosis (86); however, XNT loses its activity when combined with A-779, a selective Ang-(1-7) antagonist (72). Although the mechanisms underlying ACE2 activation have not yet been clarified, analogues have been suggested to be a good entry point for developing plant-derived ACE2-activating agents (22). XNT and its analogues are abundant in numerous plants, and some have antifungal, antibacterial, antiviral, antimalarial, anti-inflammatory and antioxidant activities (88). Therefore, further research on the mechanism of action of $\mathrm{XNT}$ is required.

\section{Hypertensive activity and functional foods}

Functional foods with antihypertensive activity have been investigated for the prevention and treatment of CVD (89). Food-derived proteins/peptides are alternatives to pharmaceutical therapeutics for regulating blood pressure (90). The antihypertensive ability of protein hydrolysates is due to their chain length and physicochemical characteristics, including hydrophobicity, molecular charge and side-chain bulkiness (91). Typically, ACE inhibitory proteins range between 3 and $10 \mathrm{kDa}(6)$. The protein is digested in vivo into 2-50-amino-acid peptides (92). Antihypertensive food peptides reportedly share structural motifs with endogenous peptides and, therefore, regulate receptors or control regulatory enzymes (93). Sources of food-derived peptides that function as ACEi include animal and plant hydrolysates, and synthetic peptides (93-95). Marine protein is a primary source of cardioprotective peptides. Proteins in fish muscle and skin, and shellfish, serve as resources for the generation of antihypertensive peptides (96-98). Functional products derived from animal proteins, such as milk protein, egg white, poultry and meat are also advertised to have health benefits. Milk protein hydrolysates from casein, whey protein and $\beta$-lactoglobulin are commercialized as a bioactive ingredient of a milk-based supplement for patients with mild hypertension. Examples of such peptides include Leu-Gln-Lys-Trp, Leu-Leu-Phe and Leu-His-Leu-Pro-Leu-Pro (93-95). 
Compared with milk and other animal proteins, vegetable proteins have been investigated less extensively (99). However, peptides from plant sources, such as soy, peas and broccoli, exert marked antihypertensive effects via mechanisms, including inhibition of ACE and vasorelaxation $(2,94,100,101)$. Several ACEi candidates within the aforementioned categories have been reported. For example, enzymatic hydrolysates from leguminous plants, such as soybeans, mung beans, rice, peas and common beans (Phaseolus vulgaris L.) (99), neo-Fermented buckwheat sprouts (102), fruiting bodies of edible mushrooms (6) and peanuts (Arachis hypogaea) (103). In general, the enzymatic activity (degree of hydrolysis value) of those peptides is typically $>15 \%$, and is mediated by C-terminal Phe, Leu and Tyr residues (104-106).

Other than peptides, phenolic compounds and flavonoids from food resources exert antihypertensive effects $(107,108)$, which may be associated with their antioxidant and antimicrobial activities. For instance, flavonoids inhibit ACE through the development of complexes with metal ions in the active center of ACE in vitro. Inhibition of ACE by flavonoids is dependent on the hydroxyl groups at the 3,5- and 3',4'-positions (107).

Competitive inhibition of C-terminal peptides with hydrophobic (aromatic or branched side chain) amino acid residues results in inhibition of ACE. Tripeptides with C-terminal amino acids (e.g., Trp, Tyr or Pro), and branched aliphatic amino acids at the N-terminal, can interact with the three subsites of an active ACE catalytic site (109). For example, casein-derived antihypertensive peptides; i.e., Val-Ala-Pro, Ile-Pro-Pro, and Val-Pro-Pro, exert antihypertensive effects through interaction with enzyme catalytic sites. Furthermore, some peptide substitutions, even with isomers, can greatly influence the nature of interactions, leading to non-competitive (e.g., Leu-Trp and Ile-Tyr) and uncompetitive (e.g., Ile-Trp and Phe-Tyr) inhibition. These modes of inhibition are characterized by binding of peptides with other sites on the enzyme, leading to changes in ACE conformation and decreased activity (91). An investigation into the interactions between ACE and active site-specific inhibitors (peptides) was performed through energy analysis. Dipeptides, such as Val-Pro, Lys-Pro and Tyr-Pro, were found to form a relatively stable molecular docking with ACE in a Caco-2 intestinal model, indicating that hydrogen bonds, hydrophobic, hydrophilic and electrostatic interactions, and van der Waals forces were involved in numerous molecular interactions (110). Although the correlation between affinity binding energy and ACE inhibitory activity was not conclusively demonstrated, the study provided valuable information.

Food-derived peptides can also inhibit ACE and renin. Flaxseed protein fractions, pea hydrolysates and hemp seed protein isolates have been reported to exhibit renin-inhibitory activities (111). The mechanisms of action of these peptides may depend on their structural features (90). C-terminal bulky amino acids (e.g., Trp, Phe, and Tyr) and hydrophobic N-terminal amino acids (e.g., Ile, Leu, Ala, and Val) are associated with activity against human renin (111).

Due to differences in active sites, ACEi are generally unable to bind to ACE2. Egg white hydrolysate, for example, which is a source of ACEi, did not affect ACE2 expression in SHRs (112). ACE2 cleaves specific peptides at a Pro-X-Pro-hydrophobic/basic consensus sequence, and this activity is inhibited by dipeptides; e.g., Pro-Phe, and involves
Ang II as the substrate (113). Several small molecules, such as calactin, calotoxin, calotropin, uscharidin, uscharin and uzarigenin derived from latex (Calotropis procera), activate ACE2 through hydrogen bonding with alanine, histidine and aspartic acid (114). ACE2 is directly regulated by dietary amino acid tryptophan; i.e., amino acid deficiency affects the intestinal microbiota, inhibiting the synthesis of ACE2 (115). Fatty acids (palmitic acid, stearic acid, docosahexaenoic acid and linoleic acid) can also increase the abundance and activity of ACE2 (28).

Few investigations have focused on food-derived substances that can activate ACE2, possibly since the mechanisms and characteristics of ACE2 are not yet fully understood. ACE and ACE2 form hydrogen bonds with various amino acids, including asparagine, arginine, glutamic acid, threonine and tyrosine (114). Amino acid transport proteins are also associated with ACE2 expression. The expression of neutral amino acid transporter solute carrier family 6 member 19 (SLC6A19) is downregulated in the kidney and small intestine of ACE2 knockout animals. A study of the influence of the source of dietary protein (soybean proteins and green pea meal) on the expression of SLC6A19 and other transporters in the intestinal tract of European sea bass (Dicentrarchus labrax), reported that feed absorption was strongly associated with the expression levels of intestinal amino acid and oligopeptide transporters (116). Hernández Prada et al (86) proposed the use of the ACE2 activator XNT to activate the ACE2-Ang-(1-7)-Mas axis. XNT interacts with ACE2, which alters the conformation of the latter (86). Due to their abundance in many natural plant materials, XNT analogues may be a good entry point for developing plant-derived ACE2-activating agents (110).

Some of the peptides with ACE inhibitory activity may also serve as ACE2 activators. The casein peptide Ile-Pro-Pro resulted in ACE inhibition and ACE2 upregulation in SHRs (117). Therefore, a better understanding of the ACE2-Ang-(1-7)-Mas axis would assist development of novel food-derived sources of antihypertensive peptides. Majumder et al (118) reported a food protein-derived ACE inhibitory peptide with a novel mechanism of action. Egg ovotransferrin-derived peptides increased the expression of ACE2 in SHRs. Subsequently, ACE2 was reported to degrade the vasoconstrictor Ang II and reduce activity of the RAS. Similarly, the level of a casein-derived ACE inhibitory peptide (Ile-Pro-Pro or Pro) was correlated with ACE2 expression in SHRs, which enhances the vasodilatory effect of Ang-(1-7) and bradykininin, indicating that ACE inhibitory peptides have the potential to activate the ACE-2-Ang-(1-7)-Mas axis (119). Feeding of the bioactive tripeptides Ile-Gln-Pro (IQP) and Val-Glu-Pro (VEP) in combination with captopril to spontaneously hypertensive rats resulted in a relatively long-term (8 weeks) effect on RAS regulation. ACE, Ang II and $\mathrm{AT}_{1}$ levels were decreased, and those of the ACE2-Ang-(1-7)-Mas axis components ACE2, Ang-(1-7), AT2 and Mas receptor were increased (106). Therefore, oral administration of food-derived bioactive peptides may benefit patients with hypertension. Food-derived bioactive peptides may be effective nutraceuticals for CVD (119).

The structure-activity relationship of the ACE active site has been the focus of studies aiming to discover natural antihypertensive agents. ACE inhibition has been investigated using 
competitive and non-competitive models (120). Molecular simulation enables analysis of the mechanisms of ACE inhibition, and has been applied to analysis of peanut proteins. The active pocket of ACE was found to be occupied by a peanut peptide (103). Hydrogen, electrostatic and Pi bonds, as well as $\mathrm{Zn}^{+}$-ligand interactions, influence the level of ACE activity. Several peptide carboxyl-terminal amino acids, such as Ala, Val, Glu, Gln and Arg, can form hydrogen bonds as either an $\mathrm{H}$ donor or receptor (103). Although they have different substrate specificities, the amino acid sequence of ACE shares $40 \%$ homology with that of ACE2 (121); therefore, a similar approach may also facilitate studies of the mechanism of action of ACE2.

Recently, ACE2 therapy for CVD has been investigated. ACE2 treatment exerted a long-term effect (6 months) in bile duct ligation mice. The increased ACE2 activity was associated with a marked reduction in the Ang II to Ang-(1-7) ratio, resulting in degradation of Ang II and an increased Ang-(1-7) level (122). Oral feeding of bio-encapsulated ACE2/Ang-(1-7) to wild type $\mathrm{C} 57 \mathrm{Bl} / 6 \mathrm{~J}$ mice and $\mathrm{B} 10$. RIII mice has been found to protect the RAS axis (123). In addition, negative regulation of Ang II may act as a positive feedback mechanism for the RAS by activating ACE2 shedding via the $\mathrm{AT}_{1}$ receptor. Therefore, increased plasma ACE2 activity is suggestive of cardioprotective effects (124).

Augmentation of ACE2 is a promising therapeutic approach as it reduces the Ang II level and increases the Ang-(1-7)/Ang II ratio. ACE2 and the vasoactive peptides Ang-(1-7), Ang-(1-9) and almandine are counter-regulators of the ACE-Ang II axis, and regulate blood pressure, and cardiovascular and renal remodeling in rats, mice and humans. ACE2 acts as an ACE inhibitor, has a single active site and a 400 -fold greater affinity for Ang II compared with Ang I (121).

Food-derived peptides have efficacies similar to synthetic drugs (108). Notably, several peptides derived from food protein have antihypertensive effects in animal studies, most of which involved SHRs; hypertension in human subjects probably has a different etiology. Therefore, clinical trials of the pharmacokinetics and pharmacodynamics of antihypertensive peptides are required (90). Several other clinical studies have reported a beneficial effect of intravenous or oral administration, or as a component of the diet, of food-derived peptides. Peptide-based food products with antihypertensive effects that target the RAS system have been developed $(22,91)$. Recent advances in biochemical techniques have enabled further insight into the molecular mechanisms of antihypertensive agents (90). A systematic study of ACE inhibitory peptides reported that the amino acid sequence of a peptide influences its antihypertensive activity. Substitution or addition of a single amino acid residue increased the ACE inhibitory activity of the peptide (125). ACEi provokes a sharp increase in ACE2 expression in rats that regulates the balance of ACE and ACE2 in the circulatory angiotensin levels (126). Activation of $\mathrm{AT}_{2}$ increased the ACE2/ACE and Mas/AT1 ratios in the heart, which serve as negative regulators of the RAS (126). A similar study involving ACEi (ACEi and ARBs) reported increased ACE2 expression in rodent hearts and clinical studies. This finding suggested that ACE2 is also involved in formation of the protein complex that influences intestinal absorption of other drugs and amino acids (127).

\section{Conclusions}

The discovery of ACE2 and the ACE2-Ang-(1-7)-Mas axis has enhanced understanding of the RAS. The ACE-Ang II-AT 1 and ACE2-Ang-(1-7)-Mas axes serve a pivotal role in regulation of blood pressure and fluid balance. An improved understanding of the ACE2-Ang-(1-7)-Mas axis and the RAS will assist the treatment of hypertension and CVD by enabling development of novel peptide-based functional foods.

A growing number of natural resources, particularly food-derived compounds, are capable of regulating the RAS. Further research into the mechanisms of the ACE-Ang II-AT and ACE2-Ang-(1-7)-Mas axes may facilitate discovery of potent and safe antihypertensive agents.

The ACE2-Ang-(1-7)-Mas axis has potential as a target for the development of drugs and functional foods. However, prior to commercialization of pharmaceutical-grade bioactive peptides, further research is required on their efficacy and potential adverse or toxic effects.

\section{Acknowledgements}

The present study was supported by grants from the National Natural Science Foundation of China (grant nos. 31571772, 31671963 and 31201339), the National High Technology Research and Development Program of China (863 Program; grant no. 2013AA102205), and the Major State Research Development Program of China (grant no. 2016YFD0400604).

\section{References}

1. World Health Organization: Cardiovascular diseases (CVDs) World Health Organ, 2015.

2. Udenigwe $\mathrm{C}$ and Mohan A: Mechanisms of food protein-derived antihypertensive peptides other than ACE inhibition. J Funct Foods 8: 45-52, 2014.

3. World Health Organization: World health statistics 2012. World Health Organ (edition.), Geneva, Switzerland, 2012.

4. Kearney PM, Whelton M, Reynolds K, Muntner P, Whelton PK and He J: Global burden of hypertension: Analysis of worldwide data. Lancet 365: 217-223, 2005.

5. World Health Organization: World health day 2013: Measure your blood pressure, reduce your risk. World Health Organ (WHO), 2013.

6. Lau CC, Abdullah N, Shuib AS and Aminudin N: Proteomic analysis of antihypertensive proteins in edible mushrooms. J Agric Food Chem 60: 12341-12348, 2012.

7. World Health Organization: A global brief on hypertension: Silent killer, global public health crisis, 2013.

8. Floyer MA: Renal control of interstitial space compliance: A physiological mechanism which may play a part in the etiology of hypertension. Clin Nephrol 4: 152-156, 1975.

9. Christiansen KM, Qureshi F, Schaible A, Park S and Gittelsohn J: Environmental factors that impact the eating behaviors of low-income African American adolescents in Baltimore City. J Nutr Educ Behav 45: 652-660, 2013.

10. De Leo F, Panarese S, Gallerani R and Ceci LR: Angiotensin converting enzyme (ACE) inhibitory peptides: Production and implementation of functional food. Curr Pharm Des 15: 3622-3643, 2009

11. Li GH, Le G, Shi YH and Shrestha S: Angiotensin I-converting enzyme inhibitory peptides derived from food proteins and their physiological and pharmacological effects. Nutr Res 24: 469-486, 2004.

12. Bergman PQ and Tigerstedt R: Niere and kreislauf. Acta Physiol 8: 223-271, 1898.

13. Bader M: Tissue renin-angiotensin-aldosterone systems: Targets for pharmacological therapy. Annu Rev Pharmacol Toxicol 50: 439-465, 2010. 
14. Unger T: The role of the renin-angiotensin system in the development of cardiovascular disease. Am J Cardiol 89: 3A-10A, 2002.

15. Kokubu T, Ueda E, Joh T and Nishimura K: Purification and properties of angiotensin I-converting enzyme in human lung and its role on the metabolism of vasoactive peptides in pulmonary circulation. Adv Exp Med Biol 120B: 467-475, 1979.

16. Touyz RM: Reactive oxygen species and angiotensin II signaling in vascular cells: Implications in cardiovascular disease. Braz J Med Biol Res 37: 1263-1273, 2004.

17. Remková A and Remko M: The role of renin-angiotensin system in prothrombotic state in essential hypertension. Physiol Res 59: 13-23, 2010.

18. Ferreira AJ, Santos RA, Bradford CN, Mecca AP, Sumners C, Katovich MJ and Raizada MK: Therapeutic implications of the vasoprotective axis of the renin-angiotensin system in cardiovascular diseases. Hypertension 55: 207-213, 2010.

19. Ferreira AJ and Santos RA: Cardiovascular actions of angiotensin-(1-7). Braz J Med Biol Res 38: 499-507, 2005.

20. Iwai M and Horiuchi M: Devil and angel in the renin-angiotensin system: ACE-angiotensin II-AT1 receptor axis vs. ACE2-angiotensin-(1-7)-Mas receptor axis. Hypertens Res 32: 533-536, 2009.

21. Saleh AS, Zhang Q and Shen Q: Recent research in antihypertensive activity of food protein-derived hydrolyzates and peptides. Crit Rev Food Sci Nutr 56: 760-787, 2016.

22. Guang C, Phillips RD, Jiang B and Milani F: Three key proteases-angiotensin-I-converting enzyme (ACE), ACE2 and renin-within and beyond the renin-angiotensin system. Arch Cardiovasc Dis 105: 373-385, 2012.

23. Savoia C, D'Agostino M, Lauri F and Volpe M: Angiotensin type 2 receptor in hypertensive cardiovascular disease. Curr Opin Nephrol Hypertens 20: 125-132, 2011.

24. Widdop RE, Matrougui K, Levy BI and Henrion D: AT2 receptor-mediated relaxation is preserved after long-term AT1 receptor blockade. Hypertension 40: 516-520, 2002.

25. Weir MR and Dzau VJ: The renin-angiotensin-aldosterone system: A specific target for hypertension management. Am J Hypertens 12: 205S-213S, 1999.

26. Tipnis SR, Hooper NM, Hyde R, Karran E, Christie G and Turner AJ: A human homolog of angiotensin-converting enzyme. Cloning and functional expression as a captopril-insensitive carboxypeptidase. J Biol Chem 275: 33238-33243, 2000.

27. Donoghue M, Hsieh F, Baronas E, Godbout K, Gosselin M, Stagliano N, Donovan M, Woolf B, Robison K, Jeyaseelan R, et al: A novel angiotensin-converting enzyme-related carboxypeptidase (ACE2) converts angiotensin I to angiotensin 1-9. Circ Res 87: E1-E9, 2000.

28. Gupte M: Role of angiotension converting enzyme 2 (ACE2) in obesity-associated hypertension. Univer Kentucky, 2011.

29. Ferreira AJ and Raizada MK: Are we poised to target ACE2 for the next generation of antihypertensives? J Mol Med (Berl) 86: 685-690, 2008

30. McKinney CA, Fattah C, Loughrey CM, Milligan G and Nicklin SA: Angiotensin-(1-7) and angiotensin-(1-9): Function in cardiac and vascular remodelling. Clin Sci (Lond) 126: 815-827, 2014.

31. Varagic J, Ahmad S, Nagata S and Ferrario CM: ACE2: Angiotensin II/angiotensin-(1-7) balance in cardiac and renal injury. Curr Hypertens Rep 16: 420, 2014.

32. Vickers C, Hales P, Kaushik V,Dick L, Gavin J, Tang J, Godbout K, Parsons T, Baronas E, Hsieh F, et al: Hydrolysis of biological peptides by human angiotensin-converting enzyme-related carboxypeptidase. J Biol Chem 277: 14838-14843, 2002.

33. Ferrario CM, Trask AJ and Jessup JA: Advances in biochemical and functional roles of angiotensin-converting enzyme 2 and angiotensin-(1-7) in regulation of cardiovascular function. Am J Physiol Heart Circ Physiol 289: H2281-H2290, 2005.

34. Santos RA, Simoes e Silva AC, Maric C, Silva DM, Machado RP, de Buhr I, Heringer-Walther S, Pinheiro SV, Lopes MT, Bader M, et al: Angiotensin-(1-7) is an endogenous ligand for the G protein-coupled receptor Mas. Proc Natl Acad Sci USA 100: 8258-8263, 2003.

35. Rice GI, Thomas DA, Grant PJ, Turner AJ and Hooper NM: Evaluation of angiotensin-converting enzyme (ACE), its homologue ACE2 and neprilysin in angiotensin peptide metabolism. Biochem J 383: 45-51, 2004.

36. Davie AP and McMurray JJ: Effect of angiotensin-(1-7) and bradykinin in patients with heart failure treated with an ACE inhibitor. Hypertension 34: 457-460, 1999.
37. Tallant EA, Lu X, Weiss RB, Chappell MC and Ferrario CM: Bovine aortic endothelial cells contain an angiotensin-(1-7) receptor. Hypertension 29: 388-393, 1997.

38. Tallant EA, Ferrario CM and Gallagher PE: Angiotensin-(1-7) inhibits growth of cardiac myocytes through activation of the mas receptor. Am J Physiol Heart Circ Physiol 289: H1560-H1566, 2005.

39. Fraga-Silva RA, Sorg BS, Wankhede M, Dedeugd C, Jun JY, Baker MB, Li Y, Castellano RK, Katovich MJ, Raizada MK and Ferreira AJ: ACE2 activation promotes antithrombotic activity. Mol Med 16: 210-215, 2010.

40. Gironacci MM, Brosnihan KB, Ferrario CM, Gorzalczany S, Verrilli MA, Pascual M, Taira C and Peña C: Increased hypothalamic angiotensin-(1-7) levels in rats with aortic coarctation-induced hypertension. Peptides 28: 1580-1585, 2007.

41. Dias-Peixoto MF, Ferreira AJ, Almeida PW, Braga VB, Coutinho DC, Melo DS, Gomes Filho A, Melo MB, Greco L, Campagnole-Santos MJ, et al: The cardiac expression of Mas receptor is responsive to different physiological and pathological stimuli. Peptides 35: 196-201, 2012.

42. Metzger R, Bader M, Ludwig T, Berberich C, Bunnemann B and Ganten D: Expression of the mouse and rat mas proto-oncogene in the brain and peripheral tissues. FEBS Lett 357: 27-32, 1995.

43. Pinheiro SV, Ferreira AJ, Kitten GT, da Silveira KD, da Silva DA, Santos SH, Gava E, Castro CH, Magalhães JA, da Mota RK, et al: Genetic deletion of the angiotensin-(1-7) receptor Mas leads to glomerular hyperfiltration and microalbuminuria. Kidney Int 75: 1184-1193, 2009.

44. Alenina N, Xu P, Rentzsch B, Patkin EL and Bader M: Genetically altered animal models for Mas and angiotensin-(1-7). Exp Physiol 93: 528-537, 2008.

45. Ferreira AJ, Jacoby BA, Araújo CA, Macedo FA, Silva GA, Almeida AP, Caliari MV and Santos RA: The nonpeptide angiotensin-(1-7) receptor Mas agonist AVE-0991 attenuates heart failure induced by myocardial infarction. Am J Physiol Heart Circ Physiol 292: H1113-H1119, 2007.

46. Fraga-Silva RA, Pinheiro SV, Gonçalves AC, Alenina N, Bader M and Santos RA: The antithrombotic effect of angiotensin-(1-7) involves mas-mediated NO release from platelets. Mol Med 14: 28-35, 2008.

47. Santos RA, Ferreira AJ, Verano-Braga $T$ and Bader M: Angiotensin-converting enzyme 2, angiotensin-(1-7) and Mas: New players of the renin-angiotensin system. J Endocrinol 216: R1-R17, 2013

48. Crackower MA, Sarao R, Oudit GY, Yagil C, Kozieradzki I, Scanga SE, Oliveira-dos-Santos AJ, da Costa J, Zhang L, Pei Y, et al: Angiotensin-converting enzyme 2 is an essential regulator of heart function. Nature 417: 822-828, 2002.

49. Oudit GY, Crackower MA, Backx PH and Penninger JM: The role of ACE2 in cardiovascular physiology. Trends Cardiovas Med 13: 93-101, 2003.

50. Mercure C, Yogi A, Callera GE, Aranha AB, Bader M, Ferreira AJ, Santos RA, Walther T, Touyz RM and Reudelhuber TL: Angiotensin(1-7) blunts hypertensive cardiac remodeling by a direct effect on the heart. Circ Res 103: 1319-1326, 2008.

51. Rentzsch B, Todiras M, Iliescu R, Popova E, Campos LA, Oliveira ML, Baltatu OC, Santos RA and Bader M: Transgenic angiotensin-converting enzyme 2 overexpression in vessels of SHRSP rats reduces blood pressure and improves endothelial function. Hypertension 52: 967-973, 2008.

52. Chhabra KH, Pedersen KB, Shenoy V, Raizada MK and Lazartigues E: ACE2 reduces hyperglycemia by preventing pancreatic renin angiotensin system over-activation in high fat diet-fed mice. FASEB J 26: 1093.1011, 2012.

53. Donoghue M, Wakimoto H, Maguire CT, Acton S, Hales P, Stagliano N, Fairchild-Huntress V, Xu J, Lorenz JN, Kadambi V, et al: Heart block, ventricular tachycardia, and sudden death in ACE2 transgenic mice with downregulated connexins. J Mol Cell Cardiol 35: 1043-1053, 2003.

54. Neves LA, Almeida AP, Khosla MC, Campagnole-Santos MJ and Santos RA: Effect of angiotensin-(1-7) on reperfusion arrhythmias in isolated rat hearts. Braz J Med Biol Res 30: 801-809, 1997.

55. Ferreira AJ, Santos RA and Almeida AP: Angiotensin-(1-7): Cardioprotective effect in myocardial ischemia/reperfusion. Hypertension 38: 665-668, 2001.

56. Díez-Freire C, Vázquez J, Correa de Adjounian MF, Ferrari MF, Yuan L, Silver X, Torres R and Raizada MK: ACE2 gene transfer attenuates hypertension-linked pathophysiological changes in the SHR. Physiol Genomics 27: 12-19, 2006. 
57. Funke A, General S, Terebesi I, Zurth C, Alincic-kunz S, Schafer M, Holler T and Diefenbach K: Estradiol-containing drug delivery system. Patents, 2011.

58. Heitsch $\mathrm{H}$, Brovkovych S, Malinski $\mathrm{T}$ and Wiemer $\mathrm{G}$ : Angiotensin-(1-7)-stimulated nitric oxide and superoxide release from endothelial cells. Hypertension 37: 72-76, 2001.

59. Sampaio WO, Souza dos Santos RA, Faria-Silva R, da Mata Machado LT, Schiffrin EL and Touyz RM: Angiotensin-(1-7) through receptor Mas mediates endothelial nitric oxide synthase activation via Akt-dependent pathways. Hypertension 49: 185-192, 2007.

60. Roks AJ, van Geel PP, Pinto YM, Buikema H, Henning RH, de Zeeuw D and van Gilst WH: Angiotensin-(1-7) is a modulator of the human renin-angiotensin system. Hypertension 34 296-301, 1999.

61. Moriguchi A, Tallant EA, Matsumura K, Reilly TM, Walton H, Ganten D and Ferrario CM: Opposing actions of angiotensin-(1-7) and angiotensin II in the brain of transgenic hypertensive rats. Hypertension 25: 1260-1265, 1995.

62. Gironacci MM, Yujnovsky I, Gorzalczany S, Taira C and Peña C: Angiotensin-(1-7) inhibits the angiotensin II-enhanced norepinephrine release in coarcted hypertensive rats. Regul Pept 118: 45-49, 2004

63. Chappell MC, Diz DI, Yunis C and Ferrario CM: Differential actions of angiotensin-(1-7) in the kidney. Kidney Int Suppl 68 S3-S6, 1998

64. Hilchey SD and Bell-Quilley CP: Association between the natriuretic action of angiotensin-(1-7) and selective stimulation of renal prostaglandin I2 release. Hypertension 25: 1238-1244, 1995

65. Luque M, Martin P, Martell N, Fernandez C, Brosnihan KB and Ferrario CM: Effects of captopril related to increased levels of prostacyclin and angiotensin-(1-7) in essential hypertension. J Hypertens 14: 799-805, 1996.

66. Fontes MA, Martins Lima A and Santos RA: Brain angiotensin-(1-7)/Mas axis: A new target to reduce the cardiovascular risk to emotional stress. Neuropeptides 56: 9-17, 2016.

67. Oscar CG, Müller-Ribeiro FC, de Castro LG, Martins Lima A, Campagnole-Santos MJ, Santos RA, Xavier CH and Fontes MA: Angiotensin-(1-7) in the basolateral amygdala attenuates the cardiovascular response evoked by acute emotional stress. Brain Res 1594: 183-189, 2015.

68. Gironacci MM: Angiotensin-(1-7): Beyond its central effects on blood pressure. Ther Adv Cardiovasc Dis 9: 209-216, 2015.

69. Chappel MC and Ferrario CM: ACE and ACE2: Their role to balance the expression of angiotensin II and angiotensin-(1-7). Kidney Int 70: 8-10, 2006.

70. Guy JL, Lambert DW, Warner FJ, Hooper NM and Turner AJ: Membrane-associated zinc peptidase families: Comparing ACE and ACE2. Biochim Biophys Acta 1751: 2-8, 2005.

71. Igase M, Strawn WB, Gallagher PE, Geary RL and Ferrario CM Angiotensin II AT1 receptors regulate ACE2 and angiotensin-(1-7) expression in the aorta of spontaneously hypertensive rats. Am J Physiol Heart Circ Physiol 289: H1013-H1019, 2005.

72. Ferreira AJ, Shenoy V, Yamazato Y, Sriramula S, Francis J Yuan L, Castellano RK, Ostrov DA, Oh SP, Katovich MJ and Raizada MK: Evidence for angiotensin-converting enzyme 2 as a therapeutic target for the prevention of pulmonary hypertension. Am J Respir Crit Care Med 179: 1048-1054, 2009.

73. Yamada K, Iyer SN, Chappell MC, Ganten D and Ferrario CM: Converting enzyme determines plasma clearance of angiotensin-(1-7). Hypertension 32: 496-502, 1998

74. Lula I, Denadai AL, Resende JM, de Sousa FB, de Lima GF, Pilo-Veloso D, Heine T, Duarte HA, Santos RA and Sinisterra RD: Study of angiotensin-(1-7) vasoactive peptide and its beta-cyclodextrin inclusion complexes: Complete sequence-specific NMR assignments and structural studies. Peptides 28: 2199-2210, 2007.

75. Marques FD, Melo MB, Souza LE, Irigoyen MC, Sinisterra RD de Sousa FB, Savergnini SQ, Braga VB, Ferreira AJ and Santos RA: Beneficial effects of long-term administration of an oral formulation of angiotensin-(1-7) in infarcted rats. Int J Hyperten 2012: 795452, 2012.

76. Kluskens LD, Nelemans SA, Rink R, de Vries L, Meter-Arkema A, Wang Y, Walther T, Kuipers A, Moll GN and Haas M: Angiotensin-(1-7) with thioether bridge: An angiotensin-converting enzyme-resistant, potent angiotensin-(1-7) analog. J Pharmacol Exp Ther 328: 849-854, 2009.

77. Durik M, van Veghel R, Kuipers A, Rink R, Haas Jimoh Akanbi M, Moll G, Danser AH and Roks AJ: The effect of the thioether-bridged, stabilized angiotensin-(1-7) analogue cyclic ang-(1-7) on cardiac remodeling and endothelial function in rats with myocardial infarction. Int J Hypertens 2012: 536426 , 2012 .
78. Wiemer G, Dobrucki LW, Louka FR, Malinski T and Heitsch $\mathrm{H}$ : AVE 0991, a nonpeptide mimic of the effects of angiotensin-(1-7) on the endothelium. Hypertension 40: 847-852, 2002.

79. Lemos VS, Silva DM, Walther T, Alenina N, Bader M and Santos RA: The endothelium-dependent vasodilator effect of the nonpeptide Ang(1-7) mimic AVE 0991 is abolished in the aorta of mas-knockout mice. J Cardiovasc Pharmacol 46: 274-279, 2005.

80. Pinheiro SV, Simões e Silva AC, Sampaio WO, de Paula RD, Mendes EP, Bontempo ED, Pesquero JB, Walther T, Alenina N, Bader M, et al: Nonpeptide AVE 0991 is an angiotensin-(1-7) receptor Mas agonist in the mouse kidney. Hypertension 44 490-496, 2004.

81. Ferreira AJ, Oliveira TL, Castro MC, Almeida AP, Castro CH, Caliari MV, Gava E, Kitten GT and Santos RA: Isoproterenol-induced impairment of heart function and remodeling are attenuated by the nonpeptide angiotensin-(1-7) analogue AVE 0991. Life sci 81: 916-923, 2007.

82. Benter IF, Yousif MH, Anim JT, Cojocel C and Diz DI: Angiotensin-(1-7) prevents development of severe hypertension and end-organ damage in spontaneously hypertensive rats treated with L-NAME. Am J Physiol Heart Circ Physiol 290: H684-H691, 2006.

83. Faria-Silva R, Duarte FV and Santos RA: Short-term angiotensin(1-7) receptor MAS stimulation improves endothelial function in normotensive rats. Hypertension 46: 948-952, 2005.

84. Singh Y, Singh K and Sharma PL: Effect of combination of renin inhibitor and Mas-receptor agonist in DOCA-salt-induced hypertension in rats. Mol Cell Biochem 373: 189-194, 2013.

85. Ferreira AJ, Shenoy V, Qi Y, Fraga-Silva RA, Santos RA, Katovich MJ and Raizada MK: Angiotensin-converting enzyme 2 activation protects against hypertension-induced cardiac fibrosis involving extracellular signal-regulated kinases. Exp Physiol 96: 287-294, 2011

86. Hernández Prada JA, Ferreira AJ, Katovich MJ, Shenoy V, Qi Y, Santos RA, Castellano RK, Lampkins AJ, Gubala V, Ostrov DA and Raizada MK: Structure-based identification of small-molecule angiotensin-converting enzyme 2 activators as novel antihypertensive agents. Hypertension 51: 1312-1317, 2008

87. Moraillon A, Gouget-Laemmel AC, Ozanam F and Chazalviel JN: Amidation of monolayers on silicon in physiological buffers: A quantitative IR study. J Phys Chem 112: 7158-7167, 2008.

88. Fotie J and Bohle DS: Pharmacological and biological activities of xanthones. Antiinfect Agents Med Chem 5: 15-31, 2006.

89. Fuentes E and Palomo I: Antiplatelet effects of natural bioactive compounds by multiple targets: Food and drug interactions. J Funct Foods: 73-81, 2013.

90. Majumder $\mathrm{K}$ and $\mathrm{Wu} \mathrm{J}$ : Molecular targets of antihypertensive peptides: Understanding the mechanisms of action based on the pathophysiology of hypertension. Int J Mol Sci 16: 256-283, 2014.

91. Udenigwe CC and Aluko RE: Food protein-derived bioactive peptides: Production, processing, and potential health benefits. J Food Sci 77: R11-R24, 2012.

92. Murray BA and FitzGerald RJ: Angiotensin converting enzyme inhibitory peptides derived from food proteins: Biochemistry, bioactivity and production. Curr Pharm Des 13: 773-791, 2007.

93. Martínez-Maqueda D, Miralles B, Recio I and Hernández-Ledesma B: Antihypertensive peptides from food proteins: A review. Food Funct 3: 350-361, 2012

94. Aleixandre A and Miguel M: Food Peptides as Antihypertensive Agents. Bioactive food proteins and peptides: 131, 2011.

95. Meisel H, Walsh D, Murray B, FitzGerald R, Mine Y and Shahidi F: ACE inhibitory peptides. Nutraceutical proteins and peptides in health and disease: 269-315, 2006.

96. Manikkam V, Vasiljevic T, Donkor ON and Mathai ML: A review of potential marine-derived hypotensive and anti-obesity peptides. Crit Rev Food Sci Nutr 56: 92-112, 2016.

97. Mora L and Hayes M: Cardioprotective cryptides derived from fish and other food sources: Generation, application and future markets. J Agric Food Chem 63: 1319-1331, 2015.

98. Choi JH, Kim KT and Kim SM: Biofunctional properties of enzymatic squid meat hydrolysate. Prev Nutr Food Sci 20: 67-72, 2015.

99. de Jesús Ariza-Ortega T,Zenón-Briones EY, Castrejón-Flores JL, Yáñez-Fernández J, de las Mercedes Gómez-Gómez Y and del Carmen Oliver-Salvador M: Angiotensin-I-converting enzyme inhibitory, antimicrobial, and antioxidant effect of bioactive peptides obtained from different varieties of common beans (Phaseolus vulgaris L.) with in vivo antihypertensive activity in spontaneously hypertensive rats. Eur Food Res Technol 239: 785-794, 2014. 
100. Marques C, Manuela Amorim M, Odila Pereira J, Pintado M, Moura D, Calhau C and Pinheiro H: Bioactive peptides-are there more antihypertensive mechanisms beyond ace inhibition? Curr Pharm Design 18: 4706-4713, 2012.

101. Li H, Prairie N, Udenigwe CC, Adebiyi AP, Tappia PS, Aukema HM, Jones PJ and Aluko RE: Blood pressure lowering effect of a pea protein hydrolysate in hypertensive rats and humans. J Agric Food Chem 59: 9854-9860, 2011.

102. Koyama M, Hattori S, Amano Y, Watanabe M and Nakamura K: Blood pressure-lowering peptides from neo-fermented buckwheat sprouts: A new approach to estimating ACE-inhibitory activity. PLoS One 9: e105802, 2014.

103. Shi A, Liu H, Liu L, Hu H, Wang Q and Adhikari B: Isolation, purification and molecular mechanism of a peanut protein-derived ACE-inhibitory peptide. PLoS One 9: e111188, 2014.

104. Ahn CB, Jeon YJ, Kim YT and Je JY: Angiotensin I converting enzyme (ACE) inhibitory peptides from salmon byproduct protein hydrolysate by Alcalase hydrolysis. Process Biochemistry 47: 2240-2245, 2012.

105. Fritz M, Vecchi B, Rinaldi G and Añón MC: Amaranth seed protein hydrolysates have in vivo and in vitro antihypertensive activity. Food Chem 126: 878-884, 2011

106. Pan H, She X, Wu H, Ma J, Ren D and Lu J: Long-term regulation of the local renin-angiotensin system in the myocardium of spontaneously hypertensive rats by feeding bioactive peptides derived from Spirulina platensis. J Agric Food Chem 63: 7765-7774, 2015

107. Wang W, Chen W, Yang Y, Liu T, Yang H and Xin Z: New phenolic compounds from coreopsis tinctoria nutt. and their antioxidant and angiotensin I-converting enzyme inhibitory activities. J Agric Food Chem 63: 200-207, 2015.

108. Saadi S, Saari N, Anwar F, Hamid AA and Mohd Ghazali H: Recent advances in food biopeptides: Production, biological functionalities and therapeutic applications. Biotechnol Adv 33: 80-116, 2015.

109. Luis CG, Mario DM, Alma MA, Gloria DO and David BA: Lima bean (Phaseolus lunatus) protein hydrolysates with ACE-I inhibitory activity. Food Nutr Sci 3: 511-521, 2012.

110. Guang C, Shang J and Jiang B: Transport of traditional Chinese pimple milk-derived angiotensin-converting enzyme (ACE) inhibitory peptides across a Caco-2 cell monolayer and their molecular recognition with ACE. J Food Agric Environ 10: 40-44, 2012

111. Haga S, Tsuchiya H,Hirai T,Hamano T, Mimori A and Ishizaka Y: A novel ACE2 activator reduces monocrotaline-induced pulmonary hypertension by suppressing the JAK/STAT and TGF- $\beta$ cascades with restored caveolin-1 expression. Exp Lung Res 41 21-31, 2015 .

112. Jahandideh F, Chakrabarti S, Majumder K, Li Q, Panahi S, Morton JS, Davidge ST and Wu J: Egg white protein hydrolysate reduces blood pressure, improves vascular relaxation and modifies aortic angiotensin II receptors expression in spontaneously hypertensive rats. J Funct Foods 27: 667-673, 2016.

113. Guy JL, Jackson RM, Acharya KR, Sturrock ED, Hooper NM and Turner AJ: Angiotensin-converting enzyme-2 (ACE2): Comparative modeling of the active site, specificity requirements, and chloride dependence. Biochemistry 42: 13185-13192, 2003.

114. Hemalatha R and Padmini E: Studies on the effect of latex of the milk weed-(Ait) R. Br. on Angiotensin Converting Enzyme (ACE) activity. Asian J Exp Sci 4: 803-807, 2010.
115. Hashimoto T, Perlot T, Rehman A, Trichereau J, Ishiguro H, Paolino M, Sigl V, Hanada T, Hanada R, Lipinski S, et al: ACE2 links amino acid malnutrition to microbial ecology and intestinal inflammation. Nature 487: 477-481, 2012.

116. Rimoldi S, Bossi E, Harpaz S, Cattaneo AG, Bernardini G, Saroglia M and Terova G: Intestinal B(0)AT1 (SLC6A19) and PEPT1 (SLC15A1) mRNA levels in European sea bass (Dicentrarchus labrax) reared in fresh water and fed fish and plant protein sources. J Nutr Sci 4: e21, 2015.

117. Chakrabarti S and Wu J: Bioactive peptides on endothelial function. Food Sci Hum Wellness 5: 1-7, 2016.

118. Majumder K, Liang G, Chen Y, Guan L, Davidge ST and Wu J: Egg ovotransferrin derived ACE inhibitory peptide IRW increases ACE2 but decreases pro-inflammatory genes expression in mesenteric artery of spontaneously hypertensive rats. Mol Nutr Food Res 59: 1735-1744, 2015.

119. Ehlers PI, Nurmi L, Turpeinen AM, Korpela R and Vapaatalo H: Casein-derived tripeptide Ile-Pro-Pro improves angiotensin-(1-7)- and bradykinin-induced rat mesenteric artery relaxation. Life sci 88: 206-211, 2011.

120. Ni H, Li L, Liu G and Hu SQ: Inhibition mechanism and model of an angiotensin I-converting enzyme (ACE)-inhibitory hexapeptide from yeast (Saccharomyces cerevisiae). PLoS One 7: e37077, 2012.

121. Mendoza-Torres E, Oyarzún A, Mondaca-Ruff D, Azocar A, Castro PF, Jalil JE, Chiong M, Lavandero S and Ocaranza MP: ACE2 and vasoactive peptides: Novel players in cardiovascular/renal remodeling and hypertension. Ther Adv Cardiovase Dis 9: 217-237, 2015.

122. Mak KY, Chin R, Cunningham SC, Habib MR, Torresi J, Sharland AF, Alexander IE, Angus PW and Herath CB: ACE2 therapy using adeno-associated viral vector inhibits liver fibrosis in mice. Mol Ther 23: 1434-1443, 2015.

123. Shil PK, Kwon KC, Zhu P, Verma A, Daniell H and Li Q: Oral delivery of ACE2/Ang-(1-7) bioencapsulated in plant cells protects against experimental uveitis and autoimmune uveoretinitis. Mol Ther 22: 2069-2082, 2014.

124. Patel VB, Clarke N, Wang Z, Fan D, Parajuli N, Basu R, Putko B, Kassiri Z, Turner AJ and Oudit GY: Angiotensin II induced proteolytic cleavage of myocardial ACE2 is mediated by TACE/ADAM-17: A positive feedback mechanism in the RAS. J Mol Cell Cardiol 66: 167-176, 2014.

125. Terashima M, Oe M, Ogura K and Matsumura S: Inhibition strength of short peptides derived from an ACE inhibitory peptide. J Agric Food Chem 59: 11234-11237, 2011.

126. Romaní-Pérez M, Outeiriño-Iglesias V, Moya CM, Santisteban P, González-Matías LC, Vigo E and Mallo F: Activation of the GLP-1 receptor by liraglutide increases ACE2 expression, reversing right ventricle hypertrophy, and improving the production of SP-A and SP-B in the lungs of type 1 diabetes rats. Endocrinology 156: 3559-3569, 2015.

127. Vuille-dit-Bille RN, Camargo SM, Emmenegger L, Sasse T, Kummer E, Jando J, Hamie QM, Meier CF, Hunziker S, Forras-Kaufmann Z, et al: Human intestine luminal ACE2 and amino acid transporter expression increased by ACE-inhibitors. Amino Acids 47: 693-705, 2015. 